\title{
ARTICLE \\ A Practical Decision Making on Design of Fixed Offshore Wind Turbine Support Structure Considering Socio-economic Impact
}

\author{
M Vishnu Surendran Sankunny* \\ Department of Ocean Engineering, Indian Institute of Technology Madras, Chennai, India
}

ARTICLE INFO

Article history:

Received: 26 December 2018

Accepted: 7 January 2019

Published: 18 January 2019

Keywords:

Wind turbine support structure

Sustainable design

Optimization

Multi criteria decision making

Non-linear based design

\section{ABSTRACT}

Wind energy is considered one of the most promising alternative energy sources against the conventional fossil fuels. However, the deployment of these structures in deep-water for better power production is considered as a complex task. This also has raised the issue regarding selection of appropriate support structures for various sea conditions by considering environmental impact and carbon footprint. This paper considers a jacket like support structure as a case study for an intermediate water depth $(50 \mathrm{~m})$. The jacket is considered to be located in North of Dutch Sea, and 100-extreme wave is applied as load condition. Here, the presented methodology provides an insight towards environmental/social impact made by the optimized designs in comparison with reference design.

\section{Introduction}

$\mathrm{F}$ ixed offshore structures are one of the most commonly used offshore structures for intermediate water depths compared to monopile. These are technically feasible and economically viable in design but are complex to design in nature. This possess many challenges in designing and execution of the project. Moreover, offshore structures are designed to resist extreme wave loading but can succumb to collapse damage due to failure of multiple components members.

One major challenges faced by industry is cost effective design of structures under extreme and normal environmental conditions. For a reliable and cost effective design under extreme loads, a non-liner static structural analysis always been a significant aspect. Computer aided structural optimization can assist in designing economical structure under various constraints like fatigue. Hence, optimization of structure has to fatigue and extreme loads under the target life. Chew et al. ${ }^{[1]}$ has considered gradient based optimization and reported the importance of buckling and fatigue load constraints over the design variables. Gentils et al. ${ }^{[2]}$ integrated Genetic algorithm (GA) and FEA (Finite Element Analysis) to optimize support structure under various constraints. The paper also reported the advantage of using meta-heuristic methods as compared to gradient based optimization. Gomes ${ }^{[3]}$ has studied the truss optimization using particle swarm optimization (PSO $)^{[4]}$ based on the reported the well behavior of the algorithm.

In most cases, API and ISO codes are used to design structures under elastic and component based design ${ }^{[5,6]}$. However, Nizamani ${ }^{[7]}$ suggested the advantage of system based design considering structure as a whole component.

*Corresponding Author:

S Surendran,

Department of Ocean Engineering, Indian Institute of Technology Madras, Chennai, India;

Emial:sur@iitm.ac.in 
The stress re-distribution between the members can result in extended load capacity towards plastic stage based design ${ }^{[8]}$. Hence the approach proposed by Ueda et. $\mathrm{al}^{\left[{ }^{[9]}\right.}$ is used in this paper by using a finite element based code, $\mathrm{USFOS}^{[10]}$.

In 2007 , as per major world leaders a $20 \%$ share of energy from renewable sources by 2020 , by making individual targets for all EU Member States ${ }^{[1]}$. The UK targets to acquire $15 \%$ of its final energy intake from renewable sources by 2020 and to decrease $\mathrm{CO}_{2}$ emissions by a minimum of $26 \%$ by 2020 and $60 \%$ by $2050^{[11]}$ and also having the best geographically varied wind resources in Europe ${ }^{[12]}$. So, it is also worth considering the social impact made by a wind energy project at various stages from manufacturing, installation and decommission stages. Lozano-Minguez et al. ${ }^{[12]}$ investigated regarding the influence of environmental factors like carbon foot, noise, and vibration, water turbidity, etc. The authors also proposed the advantage of using TOPIS (Technique for Order Preference by Similarity to Ideal Solution) method as multi criteria decision making tool.

From the above literature review, the authors understand the importance of considering socio-economic impact on decision making of offshore structural designs. Hence, this paper aims to provide an analytical methodology for the selection of the most preferable fixed jacket like support structure for a typical $5 \mathrm{MW}$ wind turbine in $50 \mathrm{~m}$ water depth. In this analysis; engineering, economics, and environmental assessment will be considered to balance the socio-economic activities of the sustainable energy sector. Figure 1 below provides sketch of offshore wind turbine (OWT) support structure under environmental loads and the methodology followed is given below Table 1.

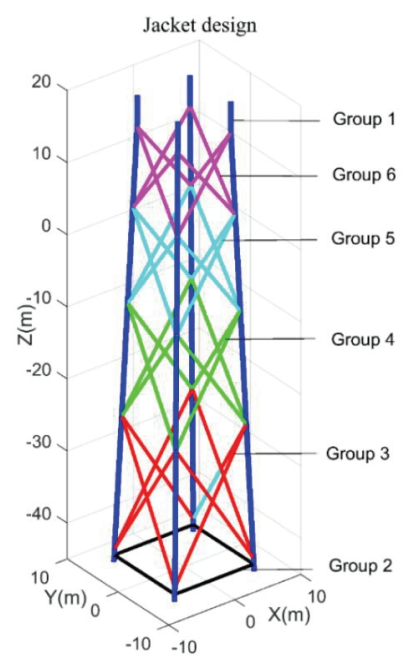

Figure 1. Jacket model
Table 1. Methodology

\begin{tabular}{c|c}
\hline Step 1 & Selection of site, loading condition and structure \\
\hline Step 2 & Evaluating optimal designs under constraints \\
\hline Step 3 & Evaluate social impact for each design \\
\hline Step 4 & TOPIS method \\
\hline
\end{tabular}

\section{Methodology}

\subsection{Step 1: Case Study}

A fixed jacket structure was proposed by Vorpahl et al. ${ }^{[13]}$ was designed to support an offshore wind turbine of 5 MW capacity. The height of the jacket structure is $66 \mathrm{~m}$ and is placed at a water depth of $50 \mathrm{~m}$. The location to be installed is considered as The North of Dutch Sea. The structure consists of 56 nodes and 104 beams of steel tubular cross section and used in this paper to perform structural optimization. The jacket structure is modelled using USFOS as shown below Figure 1. The tubular members of the jacket are categorized into six groups to utilize them for the structural optimization, and the cross sectional details of the groups are given Table 2. Also, the structure can work with stand loads even if one member is failed under yield conditions and the force redistribution happens to other members. This is indicated by factor referred as Reserve Strength Ratio (RSR) and considers the nonlinear static capacity of the structure ${ }^{[14]}$.

$$
R S R=\frac{\text { Ultimate collapseload }}{\text { Design load }}
$$

Table 2. Jacket reference design (continued)

\begin{tabular}{c|c|c|c}
\hline Design variable & Description & $\begin{array}{c}\text { Diameter } \\
(\mathrm{mm})\end{array}$ & $\begin{array}{c}\text { Thickness } \\
(\mathrm{mm})\end{array}$ \\
\hline Group 1- Dark Blue & Leg & 1200 & 50 \\
Group 2- Red & Brace & 800 & 20 \\
Group 3- Yellow & Brace & 800 & 20 \\
Group 4-Green & Brace & 800 & 20 \\
Group 5-Cyan & Brace & 800 & 20 \\
Group 6-Blue & Brace & 800 & 20 \\
\hline
\end{tabular}

The jacket material properties are given in Table 3.

\subsubsection{Hydrodynamic Loading}

The wave environment used is based on statistical wave description. Table 4 gives the significant wave height and the hydrodynamic forces acting on the tubular members are calculated using Morison's equation ${ }^{[15]}$.

As per Equation (2), the relationship between wave height and return period was formulated as:

$$
H_{s, 3 h r s}\left(T_{\text {return }}\right)=0.6127 \cdot \ln (x)+7.042
$$


Table 3. Jacket Properties

\begin{tabular}{c|c}
\hline Property & Description \\
\hline Material used & Steel \\
Elastic modulus & $2.1 \times 10^{5} \mathrm{MPa}$ \\
Poisson's modulus & 0.3 \\
Yield Strength & $345 \mathrm{MPa}$ \\
Density & $7850 \mathrm{Kg} / \mathrm{m}^{3}$ \\
Dead load & $350 \mathrm{Ton}$ \\
X joints & 16 \\
K joints & 24 \\
T/Y joints & 16 \\
Height & $66 \mathrm{~m}$ \\
Mass & $608 \mathrm{Ton}$ \\
\hline
\end{tabular}

From the 100 -year return period significant wave height, extreme design wave is calculated by the following relationship (16):

$$
H_{e}=1.86 H_{s}
$$

For the given location, the shallow water depth allows the use of 1.86 as the factor and the loading condition shown below.

Table 4. Wave data

\begin{tabular}{c|c|c}
\hline Parameter [Unit] & Description & Value \\
\hline $\mathrm{H}_{\mathrm{s}}, 100[\mathrm{~m}]$ & $\begin{array}{c}\text { Significant wave height in 100 year } \\
\text { return period }\end{array}$ & 9.90 \\
$\mathrm{H}_{\mathrm{e}}, 100[\mathrm{~m}]$ & $\begin{array}{c}\text { Extreme wave height in } 100 \text { year } \\
\text { return period }\end{array}$ & 18.41 \\
$\mathrm{~V}_{100}[\mathrm{~m} / \mathrm{s}]$ & $\begin{array}{c}\text { Mean wind speed in } 100 \text { year } \\
\text { return period }\end{array}$ & 44.50 \\
$\mathrm{U}_{100}[\mathrm{~m} / \mathrm{s}]$ & $\begin{array}{c}\text { Current speed in } 100 \text { year } \\
\text { return period }\end{array}$ & 1.20
\end{tabular}

A typical analysis for the considered reference case and given wave leading is shown below Figure 2. The load displacement curve indicates the maximum load factor or RSR. Here the RSR is evaluated as 3.6 and is over conservative as compared to minimum prescribed values of 1.58 and 1.85 provided by API and ISO respectively. However, there seems to be lack of knowledge on target RSR values for various site and loading conditions. Also, considering target values from code based methodology for offshore oil and gas structures for wind energy system may not be feasible approach. This demands multi criteria based decision making methodology in conjunction with optimization of structures to evaluate target load factor.
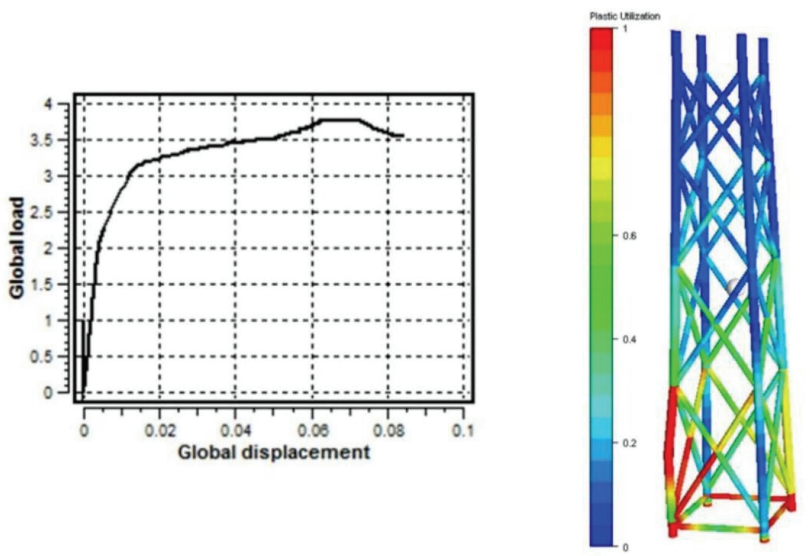

Figure 2. Typical load deflection curve for reference case

\subsection{Step 2: Integrated USFOS-MATLAB Optimi- zation}

In the present study, the evolutionary approach based particle swarm optimization (PSO) algorithm proposed by Kennedy and Eberhart is considered ${ }^{[17]}$. Perez ${ }^{[18]}$ and Gomes $^{[3]}$ reported the robustness of PSO algorithm for truss optimization. Initially, the design variable and objective functions are defined. Fitness values for each design is evaluated by integrating finite element structural analysis with PSO algorithm developed in MATLAB (Figure 3).

(a) Problem formulation

The optimization problem for minimizing structural weight with design variables, subject to sizing and ultimate collapse load factor as constraints, can be formulated as follows. The optimization problem can be formulated as given below:

Minimize jacket mass:

$$
f(x)=\sum_{i=1}^{n_{e}} \rho_{n} A_{n}(x) l_{n}
$$

Subjected to:

$$
\begin{aligned}
& \left.R S R \geq R S R_{t} \text { (varied from } 1.6 \text { to } 3.2\right) \\
& x_{L} \leq x \leq x_{U}
\end{aligned}
$$

RSR is the collapse load factor for given wave load. Here $x$ represents the vector of jacket member dimensions namely, diameter and thickness; $A$ is the vector of cross section area, $l$ represents the length of each member, $n_{e}$ represents the total number of members. This is a simplified representation of the cost function and other cost components that are incurred in the design life cycle of support structures, excluding manufacturing, installation and maintenance costs.

(b) Sizing constraints

Sizing constraints define the lower and upper bounds of 
design variables as well as the geometrical relationships among the variables. They can be expressed as

$$
g_{1}=b_{\min } \leq b \leq b_{\max }
$$

Here $b_{\min }$ and $b_{\max }$ are the lower and upper bounds of the design variables as shown in below Table 5 .

Table 5. Design bounds

\begin{tabular}{c|c|c}
\hline $\begin{array}{c}\text { Member type } \\
\text { (Group) }\end{array}$ & $\begin{array}{c}\text { Diameter bound } \\
(\mathrm{mm})\end{array}$ & $\begin{array}{c}\text { Thickness bound } \\
(\mathrm{mm})\end{array}$ \\
\hline Legs $(1)$ & $(600,1400)$ & $(30,60)$ \\
Braces $(2,3,4,5,6)$ & $(400,800)$ & $(10,30)$ \\
\hline
\end{tabular}

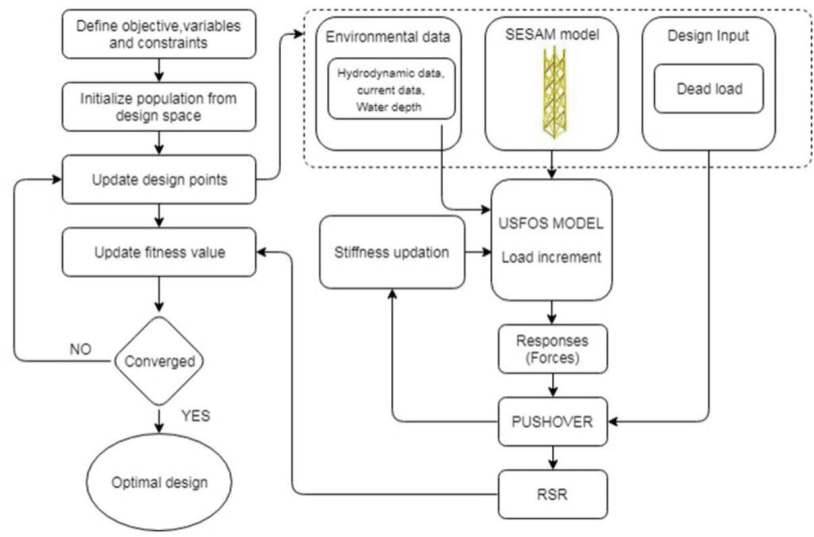

Figure 3. Integrated USFOS-MATLAB optimization framework

The results for the optimsation are shown in Table 6 for various target RSR values.

Table 6. Optimal design vs. RSR

\begin{tabular}{c|c}
\hline Mass (Ton) & RSR \\
\hline 285 & 1.6 \\
324 & 1.8 \\
365 & 2.0 \\
398 & 2.2 \\
430 & 2.4 \\
447 & 2.6 \\
480 & 2.8 \\
525 & 3.0 \\
538 & 3.2 \\
\hline
\end{tabular}

\subsection{Step 3: Economic and Environmental Impact} Assessment (EEIA)

This section will describe about the various environmental and social impact made by installation of jacket structure. This mainly includes the following factors:

(a) Carbon footprint

The equivalent amount of Carbon di Oxide $\left(\mathrm{CO}_{2}\right)$ can be expressed as following:

$$
\mathrm{CO}_{2} e=270 \times \mathrm{N}_{2} \mathrm{O}+24.5 \times \mathrm{CH}_{4}+1.4 \times \mathrm{CO}
$$

For steel structures, the emission unit per $\mathrm{kg}$ of total weight is $0.07,0.04$ and $0.93 \mathrm{~g}$ for $\mathrm{N}_{2} \mathrm{O}, \mathrm{CH}_{4}$ and $\mathrm{CO}$ respectively

(b) Noise and Vibration

As the machinery used is the same and the duration of the work will not vary significantly, it can be assumed that the choice of foundation will not affect the impact.

(c) Electromagnetic fields

However, it is not yet known whether the fish will suffer any consequences caused by this interaction. The choice of foundation will not, therefore, be considered as affecting the impact.

(d) Impact on birds

The choice of foundation will not affect the impact on birds.

(e) Net present value

This parameter will convert the total cost of the service life of the structure to present value.

\subsection{Step 4: Multi Criteria based Decision Making (TOPIS)}

As given in publicly available literature by Lozano-Minguez et al. ${ }^{[12]}$, the basic steps of multi criteria based decision making algorithm is given below. For more information, the readers are advised to refer the above paper.
(a) Formulate initial design matrix
(b) Normalized design matrix
(c) Construct weighing matrix from experts
(d) Weighted normalized decision matrix
(e) Derived PIS and NIS
(f) Evaluate relative closeness of each solution
(g) Ranking the solution

Analysis of attributes for finding the optimal design from possible nine alternative designs, nine criteria has been considered as follows (Table 7).

\begin{tabular}{|c|c|c|c|}
\hline Sl. No & Attribute & $\begin{array}{c}\text { Negative/ } \\
\text { Positive } \\
\end{array}$ & Value significance \\
\hline 1 & Artificial reefs & Positive & Higher the better \\
\hline 2 & Certification & Positive & $\begin{array}{c}\text { 1- If certified } \\
0.5 \text { - If not certified }\end{array}$ \\
\hline 3 & $\mathrm{CO}_{2} \mathrm{e}$ & Negative & Lower the better \\
\hline 4 & Depth compatibility & Negative & 1 for depth $<40 \mathrm{~m}$ \\
\hline 5 & Durability & Positive & $\begin{array}{c}5 \text { for Jacket and } 4 \text { for } \\
\text { monopile }\end{array}$ \\
\hline 6 & Life cycle cost & Negative & CAPEX + OPEX \\
\hline 7 & $\begin{array}{c}\text { Reserve strength ratio } \\
\text { (RSR) }\end{array}$ & Positive & Higher the better \\
\hline 8 & Water turbidity & Negative & $\begin{array}{l}2356 \text { for jacket and } \\
1530 \text { for monopile }\end{array}$ \\
\hline
\end{tabular}

Table 7. Description of attributes 
The weights as shown in Table 8 used for the study influence the decision approaching and has been taken from experience of experts from Cranfield offshore renewable energy group ${ }^{[12]}$.

Table 8. Weight factor for each attribute

\begin{tabular}{c|c|c|c|c|c|c|c|c}
\hline Attribute & 1 & 2 & 3 & 4 & 5 & 6 & 7 & 8 \\
\hline $\begin{array}{c}\text { Expert } \\
\text { weight }\end{array}$ & 0.65 & 0.65 & 0.91 & 0.91 & 1.00 & 1.00 & 0.83 & 0.74 \\
\hline
\end{tabular}

\section{Results and Discussion}

For the nine design combination corresponding to jacket based support structure, only the attribute 3, 6 and 7 are variables with no change for remaining. For evaluating the life cycle cost excluding risk expenditure, the capital cost (CAPEX) is evaluated considering $1000 €$ per Ton as material cost and Manufacturing cost as $400 \%$ of Material cost. For evaluating Operational cost (OPEX), it is considered as $10 \%$ of the CAPEX. However, a present worth factor should be considered to take care of the economic parameters during the life span of 20 years.

$$
P_{w}=\frac{(1+d)^{L S}-1}{d(1+d)^{L S}} / L S
$$

Below is tabulated results of LCC and RSR for each design index (Table 9).

Table 9. LCC vs. RSR for each optimal design

\begin{tabular}{c|c|c}
\hline Design Index & LCC $\left(10^{6}\right.$ Euro $)$ & RSR \\
\hline 1 & 2.92 & 1.6 \\
2 & 3.13 & 1.8 \\
3 & 3.34 & 2.0 \\
4 & 3.45 & 2.2 \\
5 & 3.62 & 2.4 \\
6 & 3.75 & 2.6 \\
7 & 3.90 & 2.8 \\
8 & 4.10 & 3.0 \\
9 & 4.21 & 3.2 \\
\hline
\end{tabular}

(a) Based on the attributes (1-8), the initial decision matrix is given below Table 10

Table 10. Initial design matrix (continued)

\begin{tabular}{c|c|c|c|c|c|c|c}
\hline 1 & 2 & 3 & 4 & 5 & 6 & 7 & 8 \\
\hline 8787 & 1 & 6036 & 1 & 5 & 2.92 & 1.6 & 2356 \\
8787 & 1 & 6863 & 1 & 5 & 3.13 & 1.8 & 2356 \\
8787 & 1 & 7730 & 1 & 5 & 3.34 & 2.0 & 2356 \\
8787 & 1 & 8492 & 1 & 5 & 3.45 & 2.2 & 2356 \\
8787 & 1 & 9107 & 1 & 5 & 3.62 & 2.4 & 2356 \\
8787 & 1 & 9465 & 1 & 5 & 3.75 & 2.6 & 2356 \\
8787 & 1 & 10166 & 1 & 5 & 3.90 & 2.8 & 2356 \\
8787 & 1 & 11200 & 1 & 5 & 4.10 & 3.0 & 2356 \\
8787 & 1 & 11395 & 1 & 5 & 4.21 & 3.2 & 2356 \\
\hline
\end{tabular}

(b) The normalized decision matrix is as follows (Table 11).

Table 11. Normalized design matrix

\begin{tabular}{c|c|c|c|c|c|c|c}
\hline 1 & 2 & 3 & 4 & 5 & 6 & 7 & 8 \\
\hline 0.58 & 0.58 & 0.22 & 0.58 & 0.58 & 0.26 & 0.21 & 0.58 \\
0.58 & 0.58 & 0.25 & 0.58 & 0.58 & 0.28 & 0.24 & 0.58 \\
0.58 & 0.58 & 0.28 & 0.58 & 0.58 & 0.30 & 0.27 & 0.58 \\
0.58 & 0.58 & 0.30 & 0.58 & 0.58 & 0.31 & 0.29 & 0.58 \\
0.58 & 0.58 & 0.33 & 0.58 & 0.58 & 0.33 & 0.32 & 0.58 \\
0.58 & 0.58 & 0.34 & 0.58 & 0.58 & 0.34 & 0.35 & 0.58 \\
0.58 & 0.58 & 0.37 & 0.58 & 0.58 & 0.35 & 0.38 & 0.58 \\
0.58 & 0.58 & 0.40 & 0.58 & 0.58 & 0.37 & 0.40 & 0.58 \\
0.58 & 0.58 & 0.41 & 0.58 & 0.58 & 0.38 & 0.43 & 0.58 \\
\hline
\end{tabular}

(c) The average normalized weight matrix is given in Table 8

(d) And the weighted normalized matrix is obtained is given as Table 12

Table 12. Weighted normalized design matrix

\begin{tabular}{c|c|c|c|c|c|c|c}
\hline 1 & 2 & 3 & 4 & 5 & 6 & 7 & 8 \\
\hline 0.38 & 0.38 & 0.20 & 0.53 & 0.58 & 0.26 & 0.17 & 0.43 \\
0.38 & 0.38 & 0.23 & 0.53 & 0.58 & 0.28 & 0.20 & 0.43 \\
0.38 & 0.38 & 0.25 & 0.53 & 0.58 & 0.30 & 0.22 & 0.43 \\
0.38 & 0.38 & 0.27 & 0.53 & 0.58 & 0.31 & 0.24 & 0.43 \\
0.38 & 0.38 & 0.30 & 0.53 & 0.58 & 0.33 & 0.27 & 0.43 \\
0.38 & 0.38 & 0.31 & 0.53 & 0.58 & 0.34 & 0.29 & 0.43 \\
0.38 & 0.38 & 0.34 & 0.53 & 0.58 & 0.35 & 0.32 & 0.43 \\
0.38 & 0.38 & 0.36 & 0.53 & 0.58 & 0.37 & 0.33 & 0.43 \\
0.38 & 0.38 & 0.37 & 0.53 & 0.58 & 0.38 & 0.36 & 0.43 \\
\hline
\end{tabular}

(f) The positive and negative ideal solution (PIS and NIS) as given in Table 13.

Table 13. PIS and NIS matrix

\begin{tabular}{c|c|c|c|c|c|c|c}
\hline 1 & 2 & 3 & 4 & 5 & 6 & 7 & 8 \\
\hline 0.38 & 0.38 & 0.20 & 0.53 & 0.58 & 0.26 & 0.36 & 0.43 \\
0.38 & 0.38 & 0.37 & 0.53 & 0.58 & 0.38 & 0.17 & 0.43 \\
\hline
\end{tabular}

After evaluating the decision matrix using TOPIS method, design index four was found to be best option (0.69). The selected index has reserve strength ratio of 2.2 with mass of 398 Ton. The RSR value is found to be well above the minimum prescribed value of 1.58 and 1.85 as per API and ISO studies respectively. 


\section{Conclusion}

The study provides a multi criteria based decision making methodology for design of offshore structures. This methodology not only considers technical feasibility, but social and economic factors for selection of optimal design. The optimal design provides technically safe and sustainable design. Further, this methodology can be extended to design of floating structures for deep water also. A sensitivity study can also be performed for change is water depth and environmental conditions.

\section{Author Contributions:}

The first author Mr. Vishnu Murali (Ph.D. scholar) has developed the methodology for design of offshore structures considering sustainability. His work includes scripting in MATLAB and FE analysis is USFOS. He has also integrated USFOS-MATLAB for seamless working of optimization methodology. The second author Prof. Surendran Sankunny has provided the necessary inspiration and motivation for the work. He has contributed significantly to the research work in detailed correction and providing technical support for numerical analysis.

\section{Conflict of Interest:}

No conflict of interest was reported by the authors.

\section{Acknowledgments:}

The first author greatly acknowledge the research grant from the Ministry of Human Resources Development, Government of India. The authors also want to thank Dr. Tore Holmas of www.usfos.no for his support that improved the quality of the paper.

\section{References}

[1] Chew K-H, Tai K, Ng EYK, Muskulus M. Analytical gradient-based optimization of offshore wind turbine substructures under fatigue and extreme loads. Mar Struct. 2016, 47, 23-41.

[2] Gentils T, Wang L, Kolios A. Integrated structural optimisation of offshore wind turbine support structures based on finite element analysis and genetic algorithm. Appl Energy. Elsevier Ltd; 2017, 199, 187-204. Available from: http://dx.doi.org/10.1016/j.apenergy.2017.05.009.

[3] Gomes HM. Truss optimization with dynamic constraints using a particle swarm algorithm. Expert Syst Appl. Elsevier Ltd; 2011;38(1):957-68. Available from: http://dx.doi. org/10.1016/j.eswa.2010.07.086.

[ 4 ] Coello C a C, Pulido GT, Lechuga MS. Handling multiple objectives with particle swarm optimization. Evol Comput IEEE Trans. 2004, 8(3), 256-79.
[ 5 ] API. Recommended Practice for Planning, Designing and Constructing Fixed Offshore Platforms - Working Stress Design. Api Recomm Pract [Internet]. 2007, 24-WSD, 242.

[6] International Organization for Standards (ISO). Petroleum and natural gas industries - Fixed steel offshore structures. Iso 19902. 2007, 2007, 638.

[7] Nizamani Z. Environmental Load Factors and System Strength Evaluation of Offshore Jacket Platforms. 2015, 128.

[ 8 ] Potty NS, Sohaimi AFA. Ultimate Strength Assessment For Fixed Steel Offshore Platform. Malaysian J Civ Eng. 2013, 25(2), 128-53.

[ 9 ] Yukio U, Rashed SMH. The idealized structural unit method and its application to deep girder structures. Comput Struct. 1984, 18(2), 277-93.

[10] SINTEF GROUP. USFOS Getting Started. 2001, 106. Available from: www.usfos.com.

[11] Carbon Trust. Offshore wind power : big challenge, big opportunity Maximising the environmental, economic and security benefits Table of Contents. Renew Energy. 2009.

[12] Lozano-Minguez E, Kolios AJ, Brennan FP. Multi-criteria assessment of offshore wind turbine support structures. Renew Energy [Internet]. Elsevier Ltd; 2011, 36(11), 2831-7. Available from: http://dx.doi.org/10.1016/j. renene.2011.04.020.

[13] Vorpahl F, Popko W, Kaufer D. Description of a basic model of the "UpWind reference jacket" for code comparison in the OC4 project under IEA Wind Annex XXX. Fraunhofer Inst Wind. 2011, 1(February), 1-14.

[14] Montes-Iturrizaga R, Heredia-Zavoni E, Vargas-Rodríguez F, Faber MH, Straub D, de Dios de la O J. Risk Based Structural Integrity Management of Marine Platforms Using Bayesian Probabilistic Nets. J Offshore Mech Arct Eng . 2009, 131(1), 11602.

[15] Abdel Raheem SE. Nonlinear behaviour of steel fixed offshore platform under environmental loads. Ships Offshore Struct. Taylor \& Francis; 2016, 11(1), 1-15. Available from: http://dx.doi.org/10.1080/17445302.2014.954301.

[16] Wei K, Myers AT. Directional effects on the reliability of non- axisymmetric support structures for offshore wind turbines under extreme wind and wave loadings. Eng Struct. Elsevier Ltd; 2016, 106:68-79. Available from: http://dx.doi.org/10.1016/j.engstruct.2015.10.016.

[17] Kennedy J, Eberhart R. Particle Swarm Optimization. 1995,1942-8.

[18] Perez RE, Behdinan K. Particle swarm approach for structural design optimization. Comput Struct. 2007, 85(1920), 1579-88. 